\title{
Circuit
}

Musiques contemporaines

\section{Kohlenstoff : collectif montréalais et étiquette de disques indépendante}

\section{Chantale Laplante}

Volume 25, numéro 1, 2015

URI : https://id.erudit.org/iderudit/1029481ar

DOI : https://doi.org/10.7202/1029481ar

Aller au sommaire du numéro

Éditeur(s)

Les Presses de l’Université de Montréal

ISSN

1183-1693 (imprimé)

1488-9692 (numérique)

Découvrir la revue

Citer ce compte rendu

Laplante, C. (2015). Compte rendu de [Kohlenstoff : collectif montréalais et étiquette de disques indépendante]. Circuit, 25(1), 84-85.

https://doi.org/10.7202/1029481ar d'utilisation que vous pouvez consulter en ligne.

https://apropos.erudit.org/fr/usagers/politique-dutilisation/ 


\section{Kohlenstoff : collectif montréalais et étiquette de disques indépendante}

Compte rendu de Chantale Laplante

Nouvelle venue dans le paysage des maisons de disques indépendantes au Québec, Kohlenstoff (Kr), fondée en 2010, compte déjà près de 20 titres à sa liste de parutions. Issue d'un collectif de musiciens-compositeurs montréalais ${ }^{1}$, la nouvelle étiquette s'inscrit dans la tradition de regroupements de créateurs dont la plateforme de diffusion reflète des objectifs artistiques particuliers, dont celui d'un contrôle sur les moyens de production ${ }^{2}$. En effet, sur le plan sociopolitique, les maisons de disques indépendantes expriment une position artistique de résistance à un nivellement des propositions musicales aux buts prioritairement mercantiles.

Ayant pour prémisse le désir de faire connaître le travail d'artistes en début de carrière, le projet artistique de Kohlenstoff s'inscrit dans ce qu'ils appellent «une scène de performances associées à la musique et à ses possibilités interdisciplinaires ${ }^{3} »$. C'est par ailleurs pour refléter leur intention d'une ouverture à une variété d'esthétiques et à des artistes de partout à travers le monde que le collectif a choisi la nomination Kohlenstoff qui correspond, en langue allemande, à l'élément carbone dans le tableau périodique, élément commun à toutes les matières organiques.

Le collectif privilégie une plateforme numérique, actualisant ainsi la médiatisation des productions musicales qui se relaient aujourd'hui principalement par un accès direct, en ligne. Reconnaissant toutefois

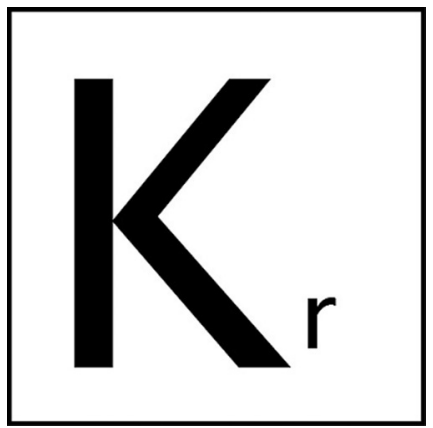

que certains projets pourraient logiquement mener à d'autres types de support, Kohlenstoff offre aussi aux artistes la possibilité de produire quelques copies physiques de leur album «que ce soit sous forme de clé USB, cassette, CD, vinyles, rouleaux de cire, etc. ${ }^{4}$ ». Dans le contexte de leur programme numérique, le site web de la maison de disques est crucial et doit pouvoir offrir une vitrine évolutive, à l'image de la pluralité des genres revendiqués. Pour le moment, le site présente pour chacun des albums un entretien filmé où l'artiste parle de sa démarche, de ses influences et de son processus de création, remplaçant ainsi en quelque sorte le livret de disque, souvent la source d'informations autrement difficilement accessibles. Enfin, il faut noter et saluer le fait que Kohlenstoff ponctue les lancements des albums par des événements-performances où se produisent les artistes et des collaborateurs et qui, ici, permet de dynamiser les liens entre l'album numérique et un art de la scène.

Le projet d'organicité, de variabilité et d'inclusivité de Kohlenstoff relève aussi de celui, large et complexe, de la musique expérimentale. Prenant 
ses racines dans les propositions d'indétermination, d'immersion, d'interactivité, ainsi que le développement et l'expérimentation de nouvelles technologies, l'«étiquette» musique expérimentale peut dans les faits adopter de nombreuses définitions. En ce qui concerne Kohlenstoff, et tel qu'il est mentionné dans leurs objectifs, leur liste d'albums reflète une diversité de pratiques issues de la performance, de pratiques multidisciplinaires et de la composition en studio, ces trois éléments se mélangeant ou non. L'ensemble des albums diffusés fait ainsi se côtoyer musiques concrète, instrumentale, noise, électroacoustique et postindustrielle d'artistes de l'Amérique du Nord, de l'Europe et du Proche-Orient. Reflet d'une mouvance interdisciplinaire, plusieurs de ces artistes œuvrent aussi dans le domaine de l'art sonore avec des productions installatives ou audiovisuelles, en plus d'être souvent actifs comme musiciens improvisateurs. En ce sens, Kohlenstoff démontre une cohérence avec ses objectifs premiers qui sont de créer des liens entre différentes esthétiques et de donner accès à des musiques en mutation perpétuelle, dans des genres parfois indéfinissables.
Le collectif montréalais Kohlenstoff convie à une réflexion sur les nouveaux modes de distribution tout en faisant état, en ce début de Xxi siècle, de la mobilité du statut de musicien. Concurremment au développement de nouvelles technologies et d'une meilleure compréhension de celles-ci, l'art musical est investi par des artistes en arts visuels et vice versa. Il est donc particulièrement intéressant qu'une maison de disques prenne note de ce mouvement en plaçant le numérique et l'interdisciplinarité au cœur de sa démarche. Projet à la fois ambitieux et inspiré, Kohlenstoff s'engage dans un chemin exigeant qui devra lui aussi être investi d'une incessante mobilité créative, pour que perdure et prolifère ce constat d'un art musical multiforme.

1. Les membres fondateurs sont Félix-Antoine Morin, Jean-François Blouin, Benoît Rolland et Maxime Corbeil-Perron.

2. À titre d'exemple, notons Ambiances magnétiques (1984), Empreintes DIGITAles (1990), Alien8 (1996), Oral (1998), Tour de bras (2006).

3. Voir: <www.kohlenstoffrecords.com> (consulté le 2 février 2015).

4. Voir: <www7.tfo.org/brbr/k-o-h-I-e-n-s-t-o-f-f-records> (consulté le 2 février 2015). 